\title{
Quinone compounds regulate the level of ROS production by the NADPH oxidase Nox4
}

\author{
Minh Vu Chuong Nguyen ${ }^{\mathrm{a}, 1, *}$, Bernard Lardy ${ }^{\mathrm{a}, \mathrm{d}, 1}$, Francis Rousset ${ }^{\mathrm{a}}$, \\ Florence Hazane-Puch ${ }^{\mathrm{e}}$, Leilei Zhang ${ }^{\mathrm{a}}$, Candice Trocmé ${ }^{\mathrm{d}}$, Lena Serrander ${ }^{\mathrm{b}}$, \\ Karl-Heinz Krause ${ }^{c}$, Françoise Morel $^{\mathrm{a}}$ \\ ${ }^{a}$ Université Joseph Fourier, GREPI AGIM FRE 3405, CNRS, EPHE, Grenoble, France \\ ${ }^{\mathrm{b}}$ Department of Clinical Microbiology, University Hospital, Linkoping, Sweden \\ ${ }^{\mathrm{c}}$ Department of Pathology and Immunology, Medical Faculty and University Hospital, Geneva, Switzerland \\ ${ }^{\mathrm{d}}$ Laboratoire de Biochimie Enzyme et Protéine-DBTP, Institut de Biologie et de Pathologie, University Hospital CHU-Grenoble, Grenoble, France \\ ${ }^{\mathrm{e}}$ Laboratoire de Biochimie Hormonale et Nutritionnelle-DBTP, Institut de Biologie et de Pathologie, University Hospital CHU-Grenoble, Grenoble, France
}

\section{A R T I C L E I N F O}

\section{Article history:}

Received 3 February 2013

Accepted 29 March 2013

Available online 9 April 2013

\section{Keywords:}

NADPH oxidase Nox 4

$\mathrm{NAD}(\mathrm{P}) \mathrm{H}$ :quinone oxidoreductase NQO1

Quinones

Redox regulation of Nox

Reactive oxygen species (ROS)

\begin{abstract}
A B S T R A C T
NADPH oxidase Nox4 is expressed in a wide range of tissues and plays a role in cellular signaling by providing reactive oxygen species (ROS) as intracellular messengers. Nox4 oxidase activity is thought to be constitutive and regulated at the transcriptional level; however, we challenge this point of view and suggest that specific quinone derivatives could modulate this activity. In fact, we demonstrated a significant stimulation of Nox 4 activity by 4 quinone derivatives (AA-861, $t B u B H Q, t B u B Q$ and duroquinone) observed in 3 different cellular models, HEK293E, T-REx ${ }^{\mathrm{TM}}$, and chondrocyte cell lines. Our results indicate that the effect is specific toward Nox4 versus Nox2. Furthermore, we showed that $\mathrm{NAD}(\mathrm{P}) \mathrm{H}$ :quinone oxidoreductase (NQO1) may participate in this stimulation. Interestingly, Nox4 activity is also stimulated by reducing agents that possibly act by reducing the disulfide bridge (Cys226, Cys270) located in the extracellular E-loop of Nox4. Such model of Nox4 activity regulation could provide new insight into the understanding of the molecular mechanism of the electron transfer through the enzyme, i.e., its potential redox regulation, and could also define new therapeutic targets in diseases in which quinones and Nox4 are implicated.
\end{abstract}

(c) 2013 Elsevier Inc. All rights reserved.

\section{Introduction}

Quinone derivative compounds induce a broad spectrum of effects in humans and represent a class of toxicological intermediates, which may induce acute cytotoxicity, immunotoxicity,

Abbreviations: AA-861, 2-(12-hydroxydodeca-5,10-diynyl)-3,5,6-trimethyl-p-benzoquinone; $\mathrm{BQ}$ benzoquinone; $\mathrm{CGD}$, chronic granulomatous disease; $\mathrm{CHX}$, cycloheximide; DPI, diphenyliodonium; Duroquinone, 2,3,5,6-tetramethyl-1,4benzoquinone; $\mathrm{HQ}$ hydroquinone; tMetBQ, 2,5-dimethyl-1,4-benzoquinone; $\mathrm{LDH}$, lactate dehydrogenase; 5-LO, 5-lipoxygenase; NQO1, NAD(P)H:quinone oxidoreductase 1; PMA, phorbol 12-myristate 13-acetate; PMN, polymorphonuclear cells; RLU, relative light unit; ROS, reactive oxygen species; $t B u B H Q, 2,5-\mathrm{di}$ tert-butyl-1,4-benzo-hydroquinone; and tBuBQ, 2,5-di-tert-butyl-1,4-benzoquinone.

* Corresponding author at: GREPI AGIM FRE 3405, CNRS, Université Joseph Fourier, EPHE, CHU Albert Michallon, BP217, 38043 Grenoble, France.

Tel.: +33 4767657 52; fax: +3347676 62 51 .

E-mail address: mvchuong@yahoo.fr (M.V.C. Nguyen).

${ }^{1}$ Equal contributors. and carcinogenesis, and lead to cellular damage [1]. They can be formed from benzene or polycyclic aromatic hydrocarbons and are toxicologically important components of air pollution [2] and cigarette smoke [3]. Among the enzymes that modulate quinone toxicity, the $\mathrm{NAD}(\mathrm{P}) \mathrm{H}$ quinone oxidoreductase type 1 (NQO1; EC 1.6.99.2) is one of the most important enzymes. NQO1 is a homodimeric flavoenzyme that catalyses the obligatory twoelectron reduction of quinones to hydroquinones [4]. NQO1 activity can protect animal cells from the deleterious and carcinogenic effects of quinones by preventing the one-electron reduction of quinones by other reductases; however, prolonged exposure to environmental contamination, which contains quinones, damages pulmonary tissue and leads to airway inflammation and pathologies through an oxidative stress mechanism [5,6]. NQO1 is mainly cytosolic but it has been described to be expressed at plasma membrane [7]. Semiquinone radicals of inhaled airborne particulate matter are believed to cause oxidative stress by generating reactive oxygen species (ROS), as reported in the lung [8]. Furthermore, diesel exhaust particles composed of polycyclic 
aromatic hydrocarbons and quinones are involved in a cellular ROS production associated with lung function impairment via a Nox4 redox-dependent mechanism [9].

Nox 4 belongs to the NADPH oxidase family that contains 7 members [10-12]. The function of those enzymes is exclusively dedicated to the production of ROS, which are essential signaling molecules. Primary discovered in kidney tissue [13], Nox4 appears to be ubiquitously distributed. Its dysfunction has been linked to several pathologies including hypertension [14], diabetes [15], atherosclerosis [16], cancer [17], osteoarthritis [18] and inflammation [19], and Nox4 represent a potential therapeutic target [20]. Despite its wide distribution, its activation mechanisms at the molecular level are unclear. It is of therapeutic interest to elucidate the mechanism of Nox4 NADPH oxidase activity. While activity of Nox1, Nox2, and Nox3 largely depends on the presence of cytosolic activator or organizer subunits, no well-known NADPH oxidase partners, beside $\mathrm{p} 22^{\text {phox }}$, have been identified or shown to activate Nox4 [21-23]. However, two partners of Nox4 have been described recently: the protein disulfide isomerase (PDI) and the polymerase DNA directed-delta-interacting protein (Poldip2). Nox4 is unique among other Nox isoenzymes in that its activity is constitutive and may depend on a specific conformation of the dehydrogenase DH domain that should allow a spontaneous transfer of electrons from NADPH to FAD and to the hemes [24,25]. Data from various studies indicated clearly that Nox4 activity is regulated at the mRNA level, implying that an increase or decrease of ROS production by Nox 4 is correlated to an up regulation $[9,16,26-33]$ or to a decline [34] of Nox4 transcripts. Although it has not been reported yet, post-translational regulation of Nox4 oxidase activity cannot be excluded.

In this study, we provide the first evidence that Nox4 activity can be modulated independently of both transcriptional and translational processes. We showed a dual effect of quinone compounds, as being activators or inhibitors of Nox4 ROS production depending on their redox potential $(E)$. We suggest that quinones derivatives could modulate Nox4 activity by a redox regulation pathway. Moreover, NQO1 is introduced as an intermediate between quinones and Nox4 activation, suggesting a functional interaction between Nox4 and NQO1. The results argue in favor of a modulation of Nox 4 activity by a new family of chemical compounds and suggest a potential role of Nox4 in pathologies implying quinone toxicity.

\section{Materials and methods}

\subsection{Materials}

Polyclonal antibody against 5-lipoxygenase (5-LO) (Cayman, Ann Arbor, USA) was a generous gift from F. Stanke (Grenoble, France). pEF6V5/HisB vector, penicillin, streptomycin, L-glutamine, Dulbecco's modified Eagle's medium (DMEM), fetal bovine serum (FBS), trypsin, Earles's balanced salts (EBSS), geneticin, Fluo-3/AM, BAPTA/ $A M$, and TRIzol ${ }^{\circledR}$ were purchased from Invitrogen (Cergy Pontoise, France). Blasticidin was from Funakoshi Co. (Japan); AMV reverse transcriptase was from QBiogene (Illkirch, France). Effectene transfection reagent was from Qiagen (Courtaboeuf, France). Luminol, ionomycin, horseradish peroxidase, thapsigargin, diphenyleneiodonium chloride (DPI), rotenone, N $\omega$-nitro-L-arginine methyl ester hydrochloride (L-NAME), tiron, xanthine, benzoquinone (BQ), hydroquinone (HQ), 2,5-dimethyl-1,4-benzoquinone ( $t$ MetBQ), duroquinone, 2,5-di-tert-butyl-1,4-benzo-hydroquinone ( $t$ BuBHQ), 2,5-di-tert-butyl-1,4-benzoquinone ( $t \mathrm{BuBQ}), \quad 2-(12-$ hydroxydodeca-5,10-diynil)-3,5,6-trimethyl-p-benzoquinone (AA861), 3,3'-methylene-bis-4-hydroxycoumarin (Dicoumarol), cycloheximide (CHX) compounds were purchased from Sigma (Saint Quentin Fallavier, France). $\beta$-Mercaptoethanol was purchased from
Carlo Erba (Val de Reuil, France). LightCycler FastStart DNA Master plus SYBR Green I kit, protease inhibitors cocktail tablet, tosyllysine-chloromethyl ketone (TLCK), NADPH, NADH, xanthine oxidase, and lactate dehydrogenase (LDH) optimized kits were purchased from Roche (Meylan, France). Leupeptin, pepstatin, and ECL reagents were from GE Healthcare (Orsay, France). UNI-ZAP human kidney lambda cDNA library was purchased from Stratagene (La Jolla, CA). Housekeeping gene GAPDH was purchased from BD Bioscience (Pont de Claix, France). SuperScriptIII first-strand synthesis was obtained from Life Technologies (Saint Aubin, France).

\subsection{Cell culture}

Nox4 T-REx ${ }^{\text {TM }}$ cells were a generous gift from K.H. Krause (Department of Pathology and Immunology, Genève, Suisse) and were generated from HEK293 cell (Invitrogen). The HEK293E cell line was purchased from Invitrogen (Cergy Pontoise, France). PLB985 human myeloid cell lines (wild type PLB-985 WT) or knock out for Nox2 (PLB-985 KO-Nox2) were a generous gift from M. Dinauer (Department of Pediatrics, St. Louis, USA). PLB-985 cells were cultured at $37{ }^{\circ} \mathrm{C}$ under a $5 \% \mathrm{CO}_{2}$ atmosphere in RPMI 1640 medium containing $2 \mathrm{mM}$ L-glutamine supplemented with $10 \%$ fetal bovine serum and with $1 \%$ penicillin/streptomycin. The HEK293E cell line was maintained in DMEM supplemented with $10 \%(\mathrm{v} / \mathrm{v})$ fetal bovine serum (FBS), 100 units $/ \mathrm{mL}$ penicillin, $100 \mu \mathrm{g} / \mathrm{mL}$ streptomycin, $2 \mathrm{mM}$ L-glutamine at $37{ }^{\circ} \mathrm{C}$ in a $5 \% \mathrm{CO}_{2}$ humidified atmosphere. Five $\mu \mathrm{g} / \mathrm{mL}$ Blasticidin was added to the culture medium of cells transfected with the mammalian expression plasmid pEF6V5/HisB.

The $\mathrm{T}-\mathrm{REx}^{\mathrm{TM}}$ system was used for Tetracycline-inducible expression of the genes of interest. T-REx ${ }^{\mathrm{TM}}$ cells stably expressing Tet repressor were selected by $5 \mu \mathrm{g} / \mathrm{mL}$ Blasticidin and maintained in DMEM supplemented with $10 \%(\mathrm{v} / \mathrm{v}) \mathrm{FBS}, 2 \mathrm{mM}$ L-glutamine at $37{ }^{\circ} \mathrm{C}$ in a $5 \% \mathrm{CO}_{2}$ humidified atmosphere. T- $\mathrm{REx}^{\mathrm{TM}}$ Nox4 cells as compared to T-REx ${ }^{\mathrm{TM}}$ WT are able to induce Nox4 expression. Both cells were selected with $5 \mu \mathrm{g} / \mathrm{mL}$ blasticidin and $400 \mu \mathrm{g} / \mathrm{mL}$ G418. Nox4 expression was induced by the addition of $1 \mu \mathrm{g} / \mathrm{mL}$ tetracycline in the culture medium. Experiments were performed after the incubation at set times.

\subsection{Isolation of human neutrophils}

As previously reported [35], human neutrophils were isolated from citrated venous blood of healthy volunteers. Blood samples were diluted twice in PBS $(137 \mathrm{mM} \mathrm{NaCl}, 2.7 \mathrm{mM} \mathrm{KCl}, 1.5 \mathrm{mM}$ $\mathrm{KH}_{2} \mathrm{PO}_{4}, 8 \mathrm{mM} \mathrm{Na}_{2} \mathrm{HPO}_{4} \mathrm{pH} 7.3$ ) containing $1 \%(\mathrm{w} / \mathrm{v}$ ) tri-sodium citrate, using a $33 \%(\mathrm{v} / \mathrm{v}$ ) Hypaque-Ficoll gradient. After $20 \mathrm{~min}$ of centrifugation at $800 \times g$ at $20^{\circ} \mathrm{C}$, the pellet was submitted to a hypotonic lysis for 5-15 min in ice. After 5 min of centrifugation at $350 \times g$ at $4{ }^{\circ} \mathrm{C}$, the neutrophil pellet was collected and washed once in PBS. Neutrophils were suspended in PBS containing $0.2 \%$ $(\mathrm{w} / \mathrm{v}) \mathrm{BSA}$ and $0.5 \mathrm{mM} \mathrm{CaCl}$ at a concentration of $10^{7}$ cells $/ \mathrm{mL}$ and used for superoxide measurement by chemiluminescence and protein extraction.

\subsection{Generation of plasmid constructs for Nox4 and NQO1 isoforms expression}

Two Nox4 cDNAs were characterized by PCR using UNI-ZAP human kidney lambda cDNA library (Stratagene) as template. Nox4A corresponds to the full length Nox4 usually described (Genbank $^{\mathrm{TM}}$ accession number: AF254621), and Nox4B is the 14 spliced exon isoform (Genbank ${ }^{\mathrm{TM}}$ accession number: AY288918). Two NQO1 cDNAs were characterized by RT-PCR from mRNA extracts of Nox4 T-REx ${ }^{\mathrm{TM}}$ cells, NQO1A (no. access NP_000894.1) and NQO1C (no. access NP_001020605.1). Nox4A, Nox4B, NQO1A, 
and NQ01C were cloned into pEF6V5/HisB for mammalian expression as described [18].

\subsection{Stable transfection of mammalian expression plasmids}

HEK293E cells were trypsinized and counted; $4 \times 10^{5}$ HEK293E cells were seeded in 6-well plates and allowed to grow for $24 \mathrm{~h}$ to reach a $60 \%$ confluence in $2 \mathrm{~mL}$ of culture medium. Cells were transfected with $0.4 \mu \mathrm{g}$ of vectors containing Nox4A or Nox4B according to the manufacturing protocol (Effectene transfection reagent, Qiagen). After $24 \mathrm{~h}$ of culture, stable transfected cells were selected by $5 \mu \mathrm{g} / \mathrm{mL}$ blasticidin for 3 weeks before analysis.

\subsection{Real time RT-PCR}

Total RNA was extracted using a TRIzol ${ }^{\circledR}$ reagent kit or RNeasy Mini Kit (Qiagen) according to the manufacturer's instructions. Total RNA was treated with RNase-free DNase I (Qiagen). One or $5 \mu \mathrm{g}$ of RNA were converted to cDNA by reverse transcription with $20 \mathrm{U}$ of AMV reverse transcriptase or SuperScriptIII first-strand synthesis (Life Technologies). Real time PCRs were performed with the LightCycler FastStart DNA Master plus SYBR Green I kit (Roche) or QuantiTect SYBR Green RT-PCR kit (Qiagen) as described [18]. Real time RT-PCR was conducted using the LightCycler ${ }^{\circledR}$ CarouselBased System (Roche) or a Stratagene Mx3005P (Stratagene). Briefly, the expression levels of human Nox4, NQO1 and housekeeping GAPDH, RPL27 and RPL32 mRNAs were determined using specific primers chosen to include intron spanning (Table 1). PCRs were carried out for each sample in triplicate. Gene expression was quantified using the comparative threshold cycle (Ct) method. The amount of target gene, normalized to three endogenous reference genes (RPL27, RPL32 and GAPDH) was expressed relative to the control cells, as indicated in Figures. The specificity of the products was confirmed for each fragment by a melting curve analysis and gel electrophoresis.

\subsection{Protein extraction}

Two methods were used. First, HEK293E cells were harvested and lysed on ice in $1 \%(\mathrm{p} / \mathrm{v})$ Triton X-100 buffer (20 mM Tris-HCl,
$150 \mathrm{mM} \mathrm{NaCl}, 1 \mathrm{mM}$ EDTA, pH 7.6), containing a protease inhibitor cocktail containing $2 \mu \mathrm{M}$ leupeptin, $2 \mu \mathrm{M}$ pepstatin, and $10 \mu \mathrm{M}$ TLCK 1 , for $20 \mathrm{~min}$ at $4{ }^{\circ} \mathrm{C}$. The lysate was then centrifuged at $10,000 \times \mathrm{g}$ for $10 \mathrm{~min}$ at $4{ }^{\circ} \mathrm{C}$ and supernatant was used for Western blotting experiments. Second, human neutrophils were suspended at a concentration of $5 \times 10^{8}$ cells $/ \mathrm{mL}$ in PBS containing the protease inhibitor cocktail. The cells were sonicated for $3 \times 10$ s at $4{ }^{\circ} \mathrm{C}$ and $40 \mathrm{~W}$ using a Branson sonifier. The homogenate was centrifuged at $1000 \times \mathrm{g}$ for $15 \mathrm{~min}$ at $4{ }^{\circ} \mathrm{C}$ to remove unbroken cells and nuclei. The post-nuclear supernatant was centrifuged at $200,000 \times g$ for $1 \mathrm{~h}$ at $4{ }^{\circ} \mathrm{C}$. The pellet consisting of crude membranes was suspended in the same buffer.

\subsection{SDS-PAGE and Western blot}

The Triton X-100 soluble extract, membrane or cytosol fractions were loaded on a $7 \%$ or $10 \%$ SDS-PAGE and electro-transferred to nitrocellulose, as previously described. Immunodetection was performed using primary polyclonal antibodies against 5-lipoxygenase (dilution 1:2000) following by a secondary antibody combined with horseradish peroxidase. The bound peroxidase activity was measured using ECL reagents.

\subsection{Determination of ROS production by chemiluminescence}

ROS production was measured as previously described [18]. Cells were washed twice with PBS, detached with trypsin, and collected by centrifugation $\left(250 \mathrm{~g}, 5 \mathrm{~min}\right.$ at $\left.20^{\circ} \mathrm{C}\right)$. The cell viability was superior to $90 \%$, as determined by the trypan blue exclusion method. For measurement of Nox 4 activity that is constitutive, $5 \times 10^{5}$ living cells per well (96-well plate) were resuspended in $250 \mu \mathrm{l}$ of PBS containing $20 \mu \mathrm{M}$ luminol and $10 \mathrm{U} / \mathrm{mL}$ horseradish peroxidase. The phagocyte oxidase (Nox2) activity was initiated by $0.13 \mu \mathrm{M}$ PMA or by $0.15 \mu \mathrm{M}$ fMLP in medium containing $0.9 \mathrm{mM} \mathrm{CaCl}_{2}, 0.5 \mathrm{mM} \mathrm{MgCl}_{2}$, and $20 \mathrm{mM}$ glucose. Relative luminescence unit (RLU) counts were recorded every minute for a total of 60 min using a Luminoscan ${ }^{\circledR}$ luminometer (Labsystems, Helsinki, Finland). In some experiments, chemical compounds (quinones) were added just before luminescence measurement (Nox4) or before the addition of

Table 1

Primers used in this study for RT-PCR experiments. tot, total and exo, exogenous.

\begin{tabular}{|c|c|c|c|}
\hline Name & Primers $\left(5^{\prime} \ldots 3^{\prime}\right)$ & Gene & $T M$ \\
\hline \multicolumn{4}{|l|}{ Real time RT-PCR } \\
\hline Nox4 Forward & CTGAATGCAGCAAGATACCGAGAT & Nox4 & $66^{\circ} \mathrm{C}$ \\
\hline Nox4 Reverse & CTGGCTTATTGCTCCGGA & Nox4 & $66^{\circ} \mathrm{C}$ \\
\hline NQ01 Forward a & GAAGAGCACTGATCGTACTGGC & NQO1 tot & $60^{\circ} \mathrm{C}$ \\
\hline NQO1 Reverse a & GGATACTGAAAGTTCGCAGGG & NQO1 tot & $60^{\circ} \mathrm{C}$ \\
\hline NQO1 Forward b & GCAAGTCCATCCCAACTGACA & NQO1 exo & $60^{\circ} \mathrm{C}$ \\
\hline NQO1 Reverse b & CTAGAAGGCACAGTCGAGGC & NQO1 exo & $60^{\circ} \mathrm{C}$ \\
\hline RPL27 Forward & TGATGGCACCTCAGATCGC & RPL27 & $60^{\circ} \mathrm{C}$ \\
\hline RPL27 Reverse & AGAGTACCTTGTGGGCATTAGG & RPL27 & $60^{\circ} \mathrm{C}$ \\
\hline RPL32 Forward & TTAAGCGTAACTGGCGGAAAC & RPL32 & $60^{\circ} \mathrm{C}$ \\
\hline RPL32 Reverse & GAGCGATCTCGGCACAGTAA & RPL32 & $60^{\circ} \mathrm{C}$ \\
\hline GAPDH Forward a & CATGAGAAGTATGACAACAGCCT & GAPDH & $60^{\circ} \mathrm{C}$ \\
\hline GAPDH Reverse a & AGTCCTTCCACGATACCAAAGT & GAPDH & $60^{\circ} \mathrm{C}$ \\
\hline GAPDH Forward b & GTGGTGGACCTGACCTGC & GAPDH & $70^{\circ} \mathrm{C}$ \\
\hline GAPDH Reverse b & CCCTGTTGCTGTAGCCAAATTCG & GAPDH & $70^{\circ} \mathrm{C}$ \\
\hline \multicolumn{4}{|c|}{ Semi-quantitative RT-PCR } \\
\hline GAPDH Forward & BD Bioscience & GAPDH & $55^{\circ} \mathrm{C}$ \\
\hline GAPDH Reverse & BD Bioscience & GAPDH & $55^{\circ} \mathrm{C}$ \\
\hline Actin Forward & Clontech & Actin & $55^{\circ} \mathrm{C}$ \\
\hline Actin Reverse & Clontech & Actin & $55^{\circ} \mathrm{C}$ \\
\hline NQO1 Forward & GTTGGTACCATGGTCGGCAGAAGAGC & NQO1 & $55^{\circ} \mathrm{C}$ \\
\hline NQO1 Reverse & GTTACTAGTTCATTTTCTAGCTTTGATCTGG & NQO1 & $55^{\circ} \mathrm{C}$ \\
\hline 5-LO Forward & CAAATGCCACAAGGATTTACCCCG & 5-Lipoxygenase & $55^{\circ} \mathrm{C}$ \\
\hline 5-LO Reverse & CGTATTTTGCATCCGAAGGGAGGA & 5-Lipoxygenase & $55^{\circ} \mathrm{C}$ \\
\hline
\end{tabular}


stimulating agents (Nox2). For the xanthine-xanthine oxidase assay, ROS production was measured as previously in a medium containing luminol and horse radish peroxidase plus $1 \mathrm{mM}$ Xanthine and $0.75 \mathrm{mUI}$ Xanthine oxidase in the presence or not of quinones.

\subsection{Intracellular free $\mathrm{Ca}^{2+}$ measurement}

Intracellular free $\mathrm{Ca}^{2+}$ levels were measured by flow cytometry (FACSCalibur, Becton Dickinson cytometer) using Fluo-3/AM. The fluorescence intensity of Fluo-3/AM dye was detected in the gated cell population at $526 \mathrm{~nm}$ (FL1 channel), which is proportional to the intracellular free calcium level. Cells were harvested and then counted. $10^{7}$ cells $/ \mathrm{mL}$, suspended in Tyrode's "free» buffer (10 mM HEPES, $145 \mathrm{mM} \mathrm{NaCl}, 2.5 \mathrm{mM} \mathrm{KCl}$, $10 \mathrm{mM}$ glucose, $1.2 \mathrm{mM} \mathrm{MgCl} 2, \mathrm{pH} 7.3$ ) were incubated in a light free environment with $10 \mu \mathrm{M}$ of Fluo-3/AM for $30 \mathrm{~min}$ at $37^{\circ} \mathrm{C}$ before analysis. After washing cells with the Tyrode's "free" buffer containing $1.5 \mathrm{mM} \mathrm{CaCl} 2$ or $1 \mathrm{mM}$ EGTA, basal fluorescence was measured at $526 \mathrm{~nm}$ for $1 \mathrm{~min}$. Chemical compounds were added to the tubes containing $5 \times 10^{6}$ cells per $500 \mu \mathrm{l}$, and measurement was continued for 5 more minutes. The data analysis was performed as follow: gates ( $5 \mathrm{~s}$ ) were created along the time axis of the dot plots windows at defined time points, and the mean fluorescence intensity was statistically analyzed for every gate (WinMDI 2.8 software).

\subsection{Lactate dehydrogenase ( $L D H)$ activity measurement}

The activity of LDH was measured in the incubation medium as an index of plasma membrane integrity. Cells were washed twice with PBS, detached with trypsin, collected by centrifugation $\left(250 \mathrm{~g}, 5 \mathrm{~min}\right.$ at $\left.20^{\circ} \mathrm{C}\right)$, and counted. In a 96-well plate, $5 \times 10^{5}$ cells per well were resuspended in $250 \mu \mathrm{l}$ of PBS. Cells were incubated with quinone compounds at different concentrations for $60 \mathrm{~min}$. At the end of the treatment period, supernatants were collected and assessed for LDH activity on a Hitachi/MODULAR automated analyzer using the Roche optimized kit. The cell viability was expressed as the percentage of $\mathrm{LDH}$ released into the incubation medium versus total cell activity measured after cell lysis with 1\% (v/v) Triton-X 100.

\subsection{Statistical analysis}

Data were expressed as the mean \pm SD. Statistical analysis was performed using Mann and Whitney or Kruskal and Wallis tests. The results are reported when significantly different $(p<0.05)$ from control.

\section{Results}

\subsection{Overexpression of Nox4 in HEK293E cell line and constitutive} NADPH oxidase activity

Nox 4 was identified for the first time in tubular cells of adult kidney and its oxidase activity was shown to be constitutive [13]. We, therefore, performed the functional characterization of Nox4 in HEK293E (human embryonic kidney) cell line which expresses Nox4 mRNA but not Nox1 and Nox2, (unpublished data). The oxidase activity of these cells was very low and was not sensitive to PMA (unpublished data). We stably overexpressed two isoforms of Nox4, Nox4A the active isoform (Genbank ${ }^{\mathrm{TM}}$ accession number: AF254621), and a splicing variant Nox4B (Genbank ${ }^{\mathrm{TM}}$ accession number: AY288918) that is unable to produce ROS due to the absence of one NADPH binding sites [36]. The results showed a significant increase of mRNA expression encoding both Nox4 isoforms compared to WT cells (Fig. 1A). While the overexpression of Nox4B failed to produce ROS, Nox4A demonstrated a spontaneous ROS generation compared to WT-HEK293E cells (Fig. 1B) and that corresponded to a NADPH oxidase activity since it was solely inhibited by DPI (inhibitor of flavoproteins) and Tiron (superoxide scavenger) but not by rotenone (mitochondrial respiratory chain inhibitor) and L-NAME (competitive inhibitor of NO synthase) (Fig. 1C).

\subsection{Stimulation of Nox4 activity by two quinone derivatives}

Next, we evaluated the effect of two quinone compounds, AA861 and $t$ BuBHQ on Nox4 constitutive activity. Incubation of Nox4A-HEK293E cells with AA-861 or $t$ BuBHQ led to an increase of ROS production (Fig. 2A). The stimulated activity reached its optimum level at $10 \mathrm{~min}$ or $20 \mathrm{~min}$ after $\mathrm{AA}-861$ or $t \mathrm{BuBHQ}$ incubation respectively. The incubation with WT-HEK293E cells did not lead to a high level of ROS production. In fact, only small increase of ROS was observed reflecting the stimulation of the endogenous Nox4 by those two quinones (Fig. 2A, inset). The specificity of a NADPH oxidase activity was confirmed by using DPI which had an inhibitory effect whereas rotenone and L-NAME did not (Fig. 2A).

To confirm that the observed effect of AA-861 and $t$ BuBHQ was specifically related to Nox4 proteins, we used two other characterized cell lines that over-expressed Nox4: human chondrocyte C-20/A4 [18] and Nox4 T-REx ${ }^{\mathrm{TM}}$ in which Nox4 expression could be temporally induced by the addition of tetracycline [27]. Consistently, the constitutive ROS production in Nox4 C-20/A4 cells or in $4 \mathrm{~h}$-induced Nox 4 T-REx cells was enhanced after the addition of AA-861 or $t$ BuBHQ (Fig. $2 \mathrm{~B}$ and C). It is noticeable that
A

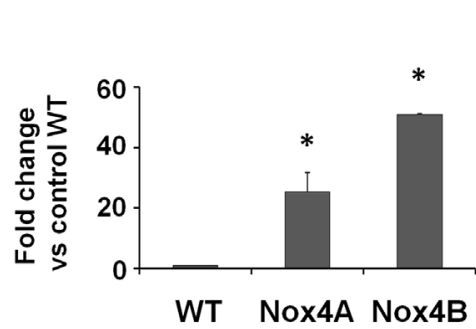

B

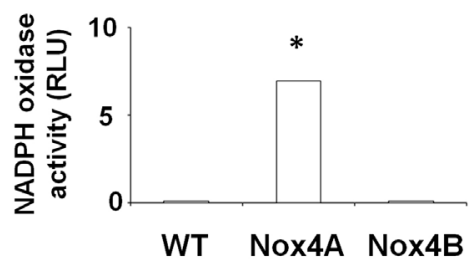

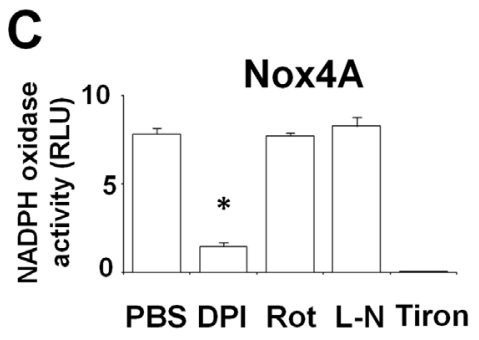

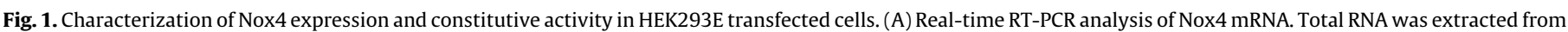

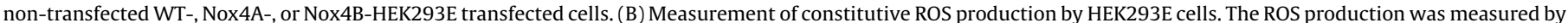

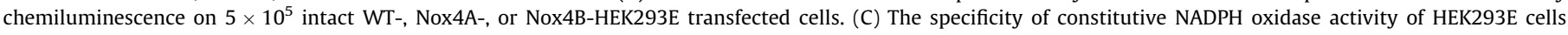

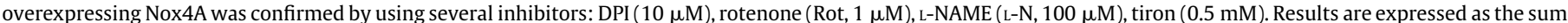

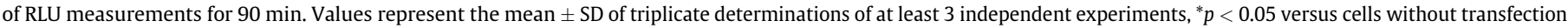
(A and B), or cells without inhibitors (C). 


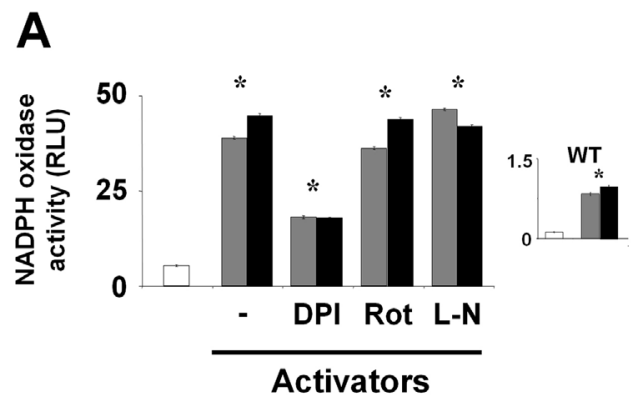

B

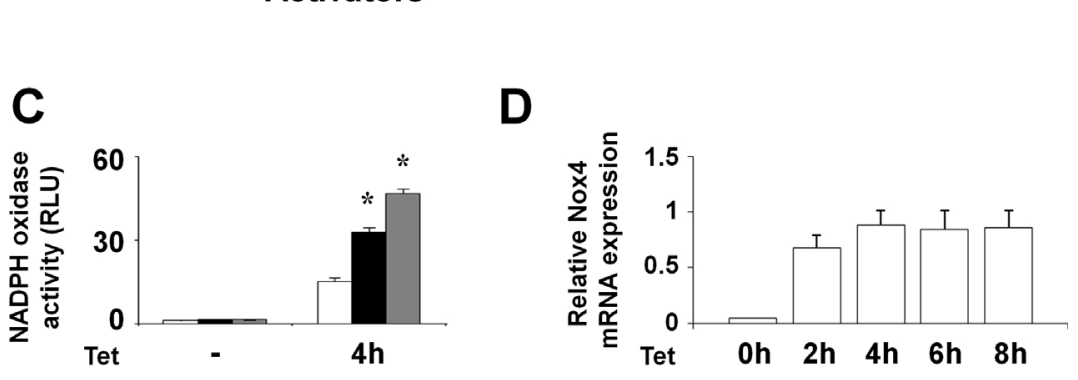

D
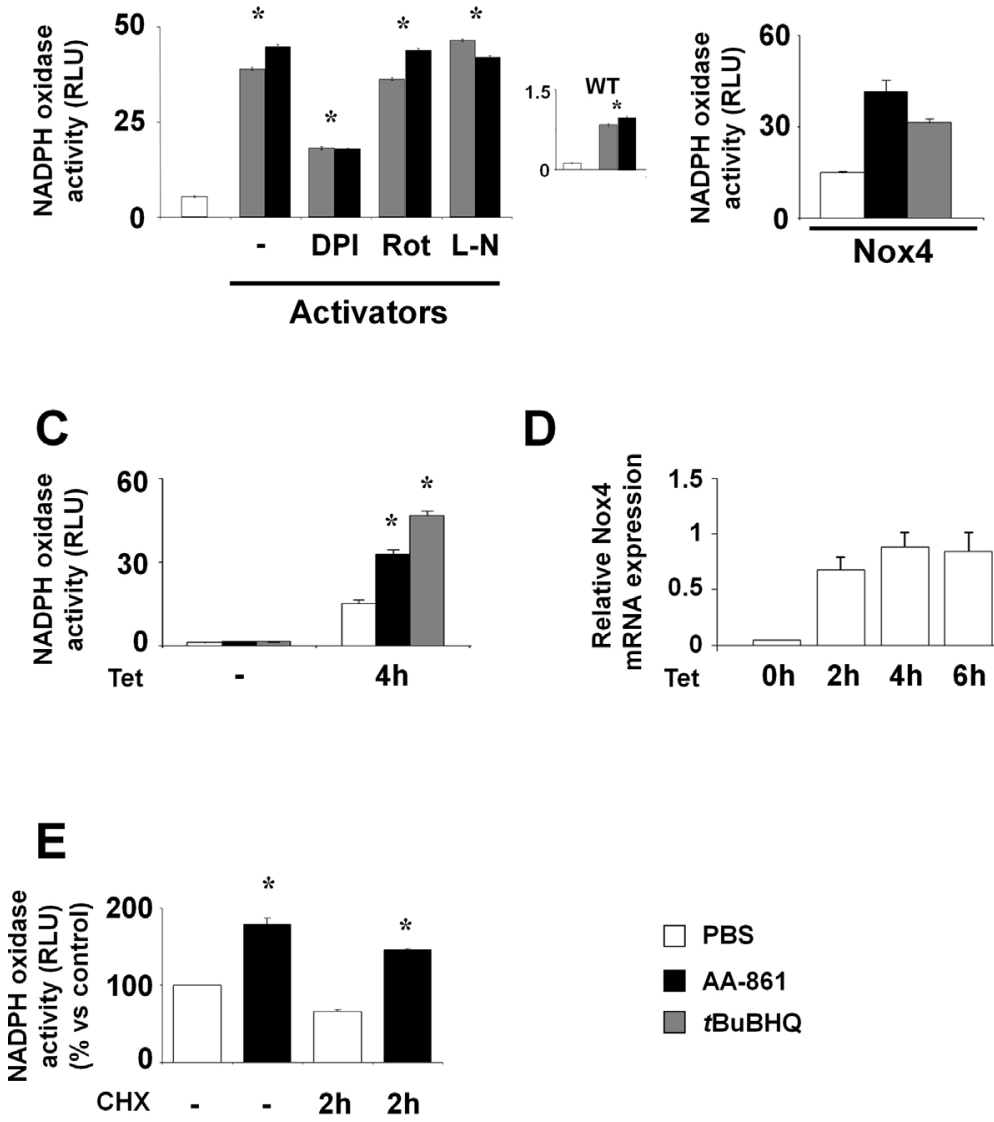

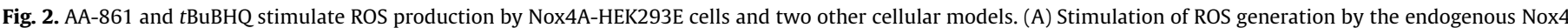

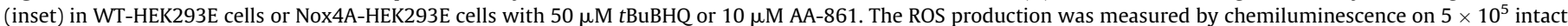

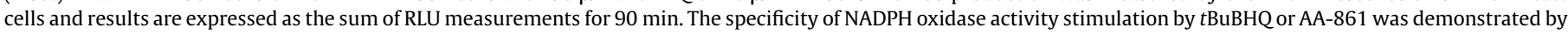

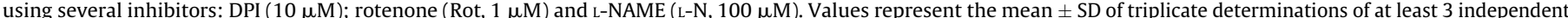

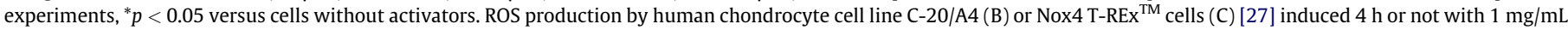

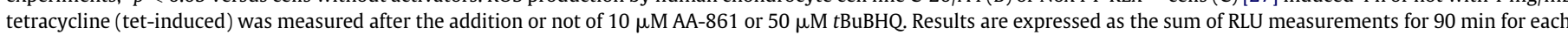

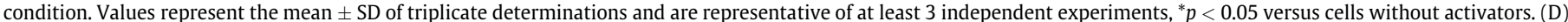

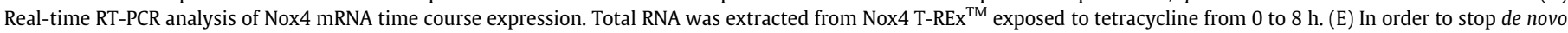

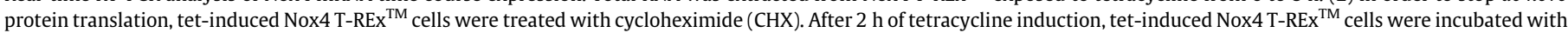

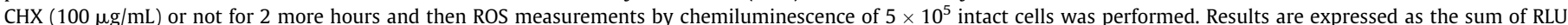

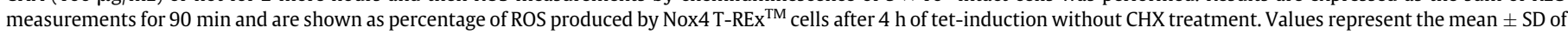
triplicate determinations of at least 3 independent experiments, ${ }^{*} p<0.05$ versus cells without AA-861 in same conditions.

the ROS production of uninduced T-REx ${ }^{\mathrm{TM}}$ cells, which do not express Nox4, was not affected by AA-861 or by $t$ BuBHQ indicating that those two quinones do not produce ROS spontaneously in the presence of cells (Fig. 2C). Considering the short time course of AA861 and $t$ BuBHQ stimulation, it is unlikely that the augmentation of Nox4 activity observed was correlated to an increase of its protein expression. However, to rule out this eventuality, we inhibited Nox4 protein synthesis by using cycloheximide (CHX), an inhibitor of protein translation. The time course of the Nox4 mRNA expression induced by tetracycline indicated that the maximum level was reached at $4 \mathrm{~h}$ and then remained constant until $8 \mathrm{~h}$ (Fig. 2D). After $2 \mathrm{~h}$ of Nox 4 induction by tetracycline, time point when the Nox4 mRNA synthesis is still increasing, CHX was added in the medium of Nox4 T-REx ${ }^{\mathrm{TM}}$ cell line and oxidase activity was measured after two additional hours of incubation. As expected, CHX-treated cells exhibited a lower constitutive oxidase activity (66\%), indicating a lower amount of induced Nox4 proteins, compared to non-CHX-treated cells (Fig. 2E, white bars). Although an increase of Nox 4 protein was abolished under CHX treatment, Nox 4 activity was still stimulated by AA-861 incubation (Fig. 2E, black bars compared to white). These results support our above consideration that AA-861 specifically increases Nox4 activity independently of its protein level.

\subsection{Molecular mechanism and significance of Nox4 activity} stimulation by quinone compounds $A A-861$ and $\mathrm{tBuBHQ}$ : 5lipoxygenase and calcium flux are not involved in the activation of Nox4

Since AA-861 was described as a 5-lipoxygenase (5-LO) inhibitor, we investigated whether 5-LO could be implicated in the stimulation of Nox 4 activity. 5-LO was originally reported to be expressed in leucocytes and some epithelial cells [37], but no data concerning 5-LO expression in the HEK293E cell line are available. We found that neither 5-LO mRNA nor 5-LO protein was expressed in HEK293E cells (Fig. 3A and B), which excludes the involvement of 5 -LO in Nox4 activation by AA-861. Furthermore, MK-886, another 5-LO inhibitor did not modulate Nox4 activity (unpublished observations).

The relationship between calcium ion flux and Nox4 activity has not been clearly described. Pedruzzi et al. [16] reported that Nox4 activity located in the endoplasmic reticulum was 
A
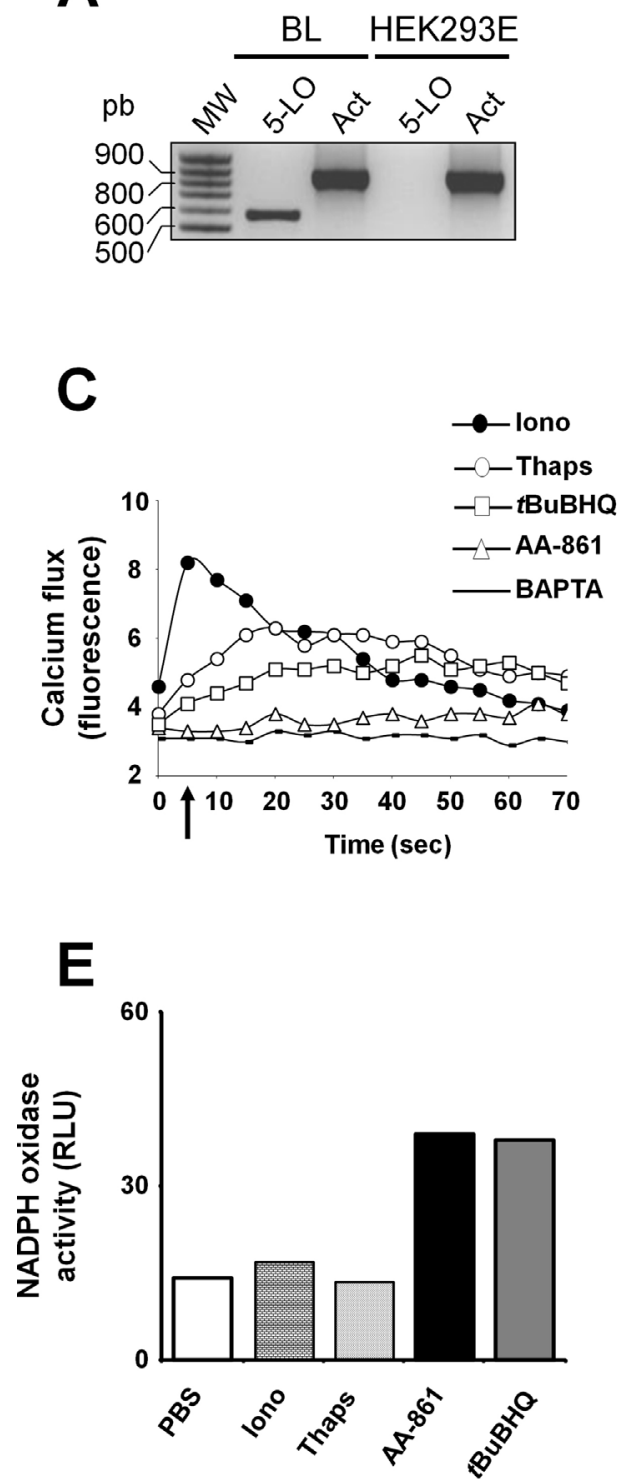

B
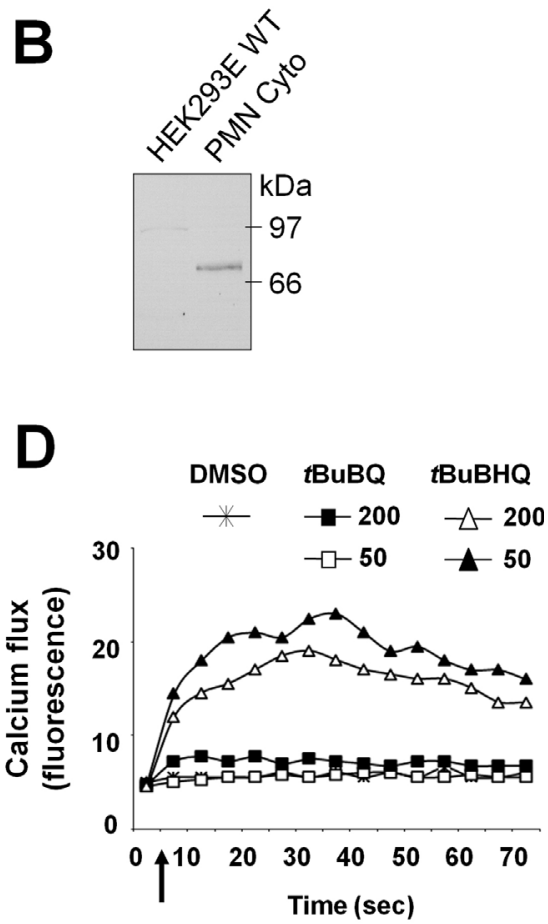

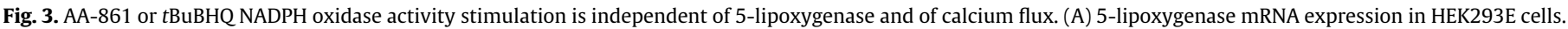

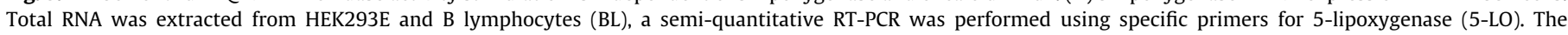

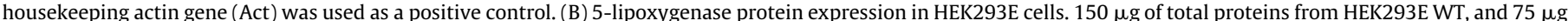

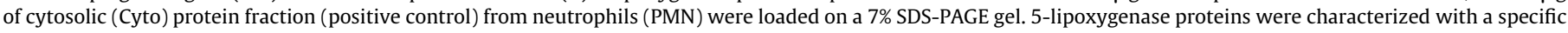

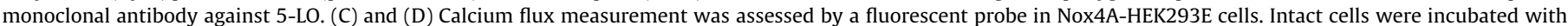

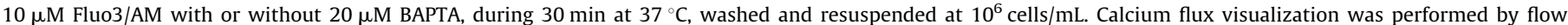

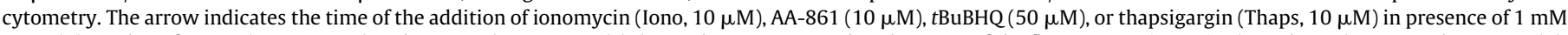

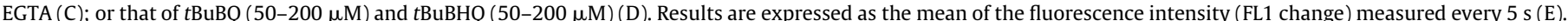

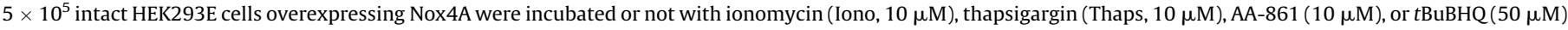
in presence of $1 \mathrm{mM}$ EGTA and then the ROS production was measured by chemiluminescence. Results are expressed as the sum of RLU measurements for 90 min.

concomitant to $\mathrm{Ca}^{2+}$ oscillation after exposure to 7-ketocholesterol. However in a previous study, we showed that ionomycin (calcium ionophore) had no effect on the Nox4 activity in chondrocytes C-20/A4 cells over-expressing Nox4A [18]. Since $t$ BuBHQ was described as a SERCA pump inhibitor, it is necessary to evaluate the potential contribution of the $\mathrm{Ca}^{2+}$ flux on Nox4 stimulation. To this purpose, we measured the calcium flux in Nox4-HEK293E cells by FACs using a fluorescent Fluo-3/AM probe and compared the calcium changes to Nox4 activation. As illustrated in the figure 3 (Fig. $3 \mathrm{C}$ and D), an increase of cytosolic calcium from intracellular stores was observed in the presence of extracellular EGTA after adding ionomycin, thapsigargin or $t \mathrm{BuBHQ}$ whereas the addition of $\mathrm{AA}-861$ or $t \mathrm{BuBQ}$ two compounds that stimulate Nox4 activity were unable to modify
$\mathrm{Ca}^{2+}$ level. Furthermore, thapsigargin or ionomycin could not modulate the constitutive activity of Nox4 in Nox4-HEK293E cells (Fig. 3E). Same experiments were performed in the presence of $1.5 \mathrm{mM} \mathrm{CaCl}_{2}$ in the extracellular medium without EGTA and led to the same results (unpublished observations). These data strongly suggest that there is no correlation between $\mathrm{Ca}^{2+}$ flux and Nox4 activity.

\subsection{Quinone structure may be responsible for the modulation of Nox4} activity

AA-861 and $t$ BuBHQ share the same quinone moiety. To evaluate whether quinone structure was responsible for Nox4 activation, the ROS production by Nox4-HEK293E cells was 
Table 2

Quinone effect on Nox4 ROS production of Nox4A-HEK293 cells. Data were expressed as the mean $\pm \mathrm{SD}$.

\begin{tabular}{|c|c|c|c|}
\hline Effect & Structure & {$[C] \mu \mathrm{M}$} & ROS production \\
\hline \multicolumn{4}{|l|}{ None } \\
\hline PBS & & & $9.01 \pm 0.8$ \\
\hline \multicolumn{4}{|l|}{ Activators } \\
\hline \multirow[t]{4}{*}{ AA-861 } & & 1 & $24.26 \pm 0.91^{*}$ \\
\hline & & 5 & $34.40 \pm 1.16^{*}$ \\
\hline & & 10 & $45.70 \pm 0.77^{*}$ \\
\hline & & 50 & $37.20 \pm 2.14^{*}$ \\
\hline \multirow[t]{4}{*}{$t$ BuBHQ } & & 1 & $14.20 \pm 0.76$ \\
\hline & & 10 & $36.01 \pm 0.68^{*}$ \\
\hline & & 50 & $61.74 \pm 0.78^{*}$ \\
\hline & & 100 & $38.90 \pm 1.82^{*}$ \\
\hline \multirow[t]{4}{*}{$t \mathrm{BuBQ}$} & & 1 & $13.58 \pm 0.42$ \\
\hline & & 10 & $32.70 \pm 0.22^{*}$ \\
\hline & & 50 & $36.50 \pm 0.63^{*}$ \\
\hline & & 100 & $34.99 \pm 1.22^{*}$ \\
\hline \multirow[t]{3}{*}{ Duroquinone } & & 1 & $35.69 \pm 1.65^{*}$ \\
\hline & & 10 & $30.21 \pm 1.70^{*}$ \\
\hline & & 50 & $29.30 \pm 1.80^{*}$ \\
\hline \multicolumn{4}{|l|}{ Inhibitors } \\
\hline \multirow[t]{5}{*}{ Benzoquinone } & & 0.01 & $7.88 \pm 0.36$ \\
\hline & & 0.5 & $8.09 \pm 0.37$ \\
\hline & & 1 & $7.69 \pm 0.51$ \\
\hline & & 3 & $3.63 \pm 0.15^{*}$ \\
\hline & $\mathrm{OH}$ & 30 & $1.01 \pm 0.11^{*}$ \\
\hline \multirow[t]{5}{*}{ Hydroquinone } & & 0.01 & $7.65 \pm 0.50$ \\
\hline & & 0.5 & $8.09 \pm 0.37$ \\
\hline & or & 1 & $8.70 \pm 0.52$ \\
\hline & & 3 & $4.18 \pm 0.34^{*}$ \\
\hline & & 30 & $0.12 \pm 0.07^{*}$ \\
\hline \multirow[t]{5}{*}{$t$ MetBQ } & & 1 & $10.09 \pm 1.68$ \\
\hline & & 10 & $12.70 \pm 0.43$ \\
\hline & & 50 & $12.87 \pm 0.82$ \\
\hline & & 100 & $1.32 \pm 0.20^{*}$ \\
\hline & & 200 & $0.38 \pm 0.01^{*}$ \\
\hline \multirow[t]{5}{*}{ Plumbagine } & & 0.01 & $7.40 \pm 0.67$ \\
\hline & & 0.5 & $6.64 \pm 0.27$ \\
\hline & $\mathrm{OH}$ & 1 & $4.00 \pm 0.22^{*}$ \\
\hline & & 5 & $1.93 \pm 0.29^{*}$ \\
\hline & & 10 & $1.34 \pm 0.09^{*}$ \\
\hline
\end{tabular}

$p<0.01$ versus PBS treated cells.

measured after incubation with various quinone derivatives that differ with respect to their reduced or oxidized state and substitution levels. The results shown in Table 2 illustrate two opposite effects. Duroquinone as well as $t \mathrm{BuBHQ}, t \mathrm{BuBQ}$ (the oxidative form of $t \mathrm{BuBHQ}$ ), and AA-861, stimulated Nox4 activity at a starting concentration of $1 \mu \mathrm{M}$, whereas BQ (30 $\mu \mathrm{M})$, HQ $(30 \mu \mathrm{M})$ and $t$ MetBQ $(100 \mu \mathrm{M})$ inhibited this activity in a dose dependent manner. We also confirmed the inhibitory effect of the naphthoquinone, plumbagin, on Nox4 activity as reported $[38,39]$.

To exclude a non-specific spontaneous ROS production by quinone compounds in contact with membrane phospholipids as described for $t \mathrm{BuBHQ}$ [40], we measured the ROS synthesis in the presence of $25 \mu \mathrm{g}$ phosphatidylcholine. The results illustrated in Table 3 show that there was no ROS enhancement by quinones after addition of phospholipids versus control, except for a slight increase observed as expected with $t$ BuBHQ as previously reported [40]. Furthermore, quinone concentrations used in this study were not cytotoxic as examined by the LDH activity (Table 3 ).

\subsection{Effect of quinones on Nox2}

We next evaluated whether those quinones could affect Nox2 oxidase activity in isolated human neutrophils which express only
Table 3

Cytotoxicity of quinones and ROS production in the presence of phosphatidylcholine.

\begin{tabular}{lrlll}
\hline Structure & {$[C] \mu \mathrm{M}$} & Toxicity \%LDH & \multicolumn{2}{l}{ ROS production ${ }^{\mathrm{b}}$} \\
\cline { 4 - 5 } & & & $\mathrm{PBS}$ & $\mathrm{PC}$ \\
\hline- & - & $10.80 \pm 0.29$ & $1.9 \pm 0.1$ & $2.7 \pm 0.2$ \\
Benzoquinone & 1 & $11.37 \pm 0.53$ & $\mathrm{ND}$ & $\mathrm{ND}$ \\
& 30 & $10.72 \pm 0.53$ & $2.0 \pm 0.1$ & $2.3 \pm 0.2$ \\
Hydroquinone & 1 & $10.73 \pm 0.53$ & $\mathrm{ND}$ & $\mathrm{ND}$ \\
& 30 & $10.99 \pm 0.80$ & $2.1 \pm 0.1$ & $2.3 \pm 0.1$ \\
tMetBQ & 50 & $12.79 \pm 0.97$ & $2.3 \pm 0.3$ & $2.4 \pm 0.1$ \\
& 200 & $12.66 \pm 1.00$ & $\mathrm{ND}$ & $\mathrm{ND}$ \\
$t$ BuBQ & 50 & $12.44 \pm 0.42$ & $2.3 \pm 0.1$ & $2.2 \pm 0.2$ \\
$t$ BuBHQ & 50 & $11.93 \pm 1.41$ & $4.4 \pm 0.9$ & $6.8 \pm 0.4$ \\
Duroquinone & 50 & $11.03 \pm 1.13$ & $2.3 \pm 0.1$ & $2.8 \pm 0.2$ \\
AA-861 & 10 & $12.00 \pm 0.84$ & $2.3 \pm 0.1$ & $2.4 \pm 0.3$ \\
\hline
\end{tabular}

a Cytotoxicity evaluation of quinone compounds on HEK293E cell line. $5 \times 10^{5}$ intact HEK293E were incubated with chemical compounds and lactate dehydrogenase (LDH) activity was assessed $60 \mathrm{~min}$ later in the culture medium. Values represent the mean percentage of $\mathrm{LDH}$ activity compared to total LDH enzymatic activity (cells lyzed by a treatment with $1 \%$ triton X-100).

b Luminol chemiluminescence measurements of quinone alone (PBS column) or with only $25 \mu \mathrm{g}$ of phosphatidylcholine (PC column) demonstrated no spontaneous ROS production. Values represent the mean percentage of NADPH oxidase activity compared to constitutive ROS production by Nox4A-HEK293E alone.

Nox2, the redox core of phagocyte NADPH oxidase. Compared to the well known activator PMA, no NADPH oxidase activation was observed when neutrophils were incubated with AA-861, $t$ BuBQ, or duroquinone (Fig. 4A) as opposed to what was previously observed in Nox4 T-REx ${ }^{\mathrm{TM}}$ cells (Table 2). However, slight oxidase activation was observed upon the addition of $t \mathrm{BuBHQ}$, probably due to its effect on the calcium flux since thapsigargin, another SERCA pump inhibitor, or ionomycin gave similar results (unpublished data). On the contrary, the quinones $\mathrm{BQ}, \mathrm{HQ}, \mathrm{tMetBQ}$ and plumbagin also inhibited the PMA stimulated neutrophil oxidase activity (Fig. 4B). By using an in vitro xanthine/xanthine oxidase superoxide production system, we observed that the ROS production was abolished in the presence of $30 \mu \mathrm{M}$ BQ, $30 \mu \mathrm{M}$ $\mathrm{HQ}$, and $100 \mu \mathrm{M} t \mathrm{MetBQ}$ while no effect on the xanthine/xanthine oxidase ROS production was noticeable with $50 \mu \mathrm{M}$ duroquinone, $50 \mu \mathrm{M} t \mathrm{BuBHQ}, 50 \mu \mathrm{M} t \mathrm{BuBQ}$ or $10 \mu \mathrm{M}$ AA-861 (unpublished data). Using differentiated PLB-985 as another cellular model, we obtained similar results than those observed with human PMN (Fig. 4C). We, next, evaluated whether quinones could increase Nox2 activity already activated by the physiological agonists (the formylated peptide fMLP) in differentiated PLB-985 cells and found that $\mathrm{AA}-861, t \mathrm{BuBQ}$ and duroquinone did not stimulate Nox2 activity (Fig. 4D).

These results suggest that BQ $\mathrm{HQ}$ and $t$ MetBQ inhibit ROS production through an antioxidant property. On the contrary, duroquinone, $t \mathrm{BuBHQ}, \mathrm{BuBQ}$, and $\mathrm{AA}-861$ appear to stimulate specifically NADPH oxidase activity of Nox4.

\subsection{Putative quinone binding site ( $Q$ site) on Nox4}

Quinones compounds bind to its target proteins through well described ubiquinone binding sites [41]. Based on computational prediction, a consensus sequence for a predictable quinone binding site or Q site was suggested: "aliphatic- $(\mathrm{X})_{3}-\mathbf{H}-(\mathrm{X})_{2-3}-(\mathbf{L e u} / \mathbf{T h r} /$ Ser)" [42]. The analysis of the Nox4 protein sequence showed a similar putative motif in the fifth transmembrane domain

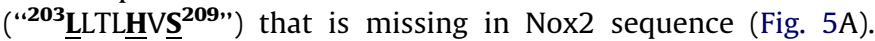
Therefore, quinones could regulate Nox4 activity by binding directly to the protein through this putative domain. To investigate the relevance of this potential Q site in Nox4 protein, we mutated 
A
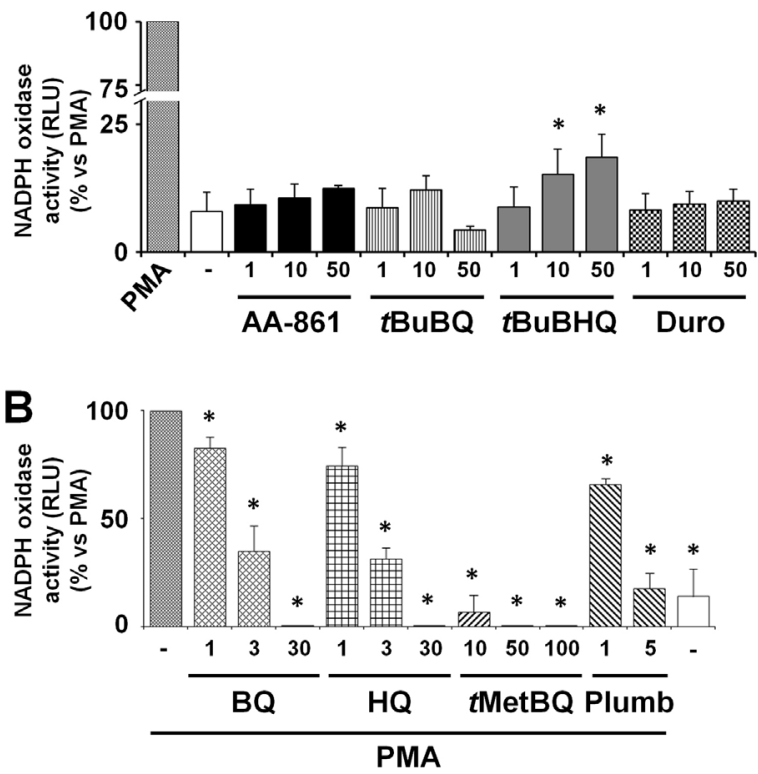

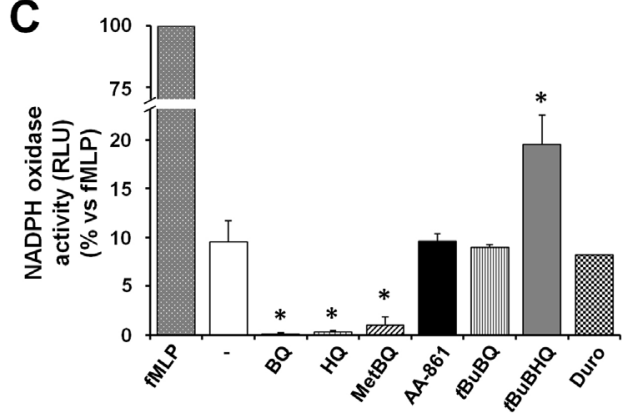

D

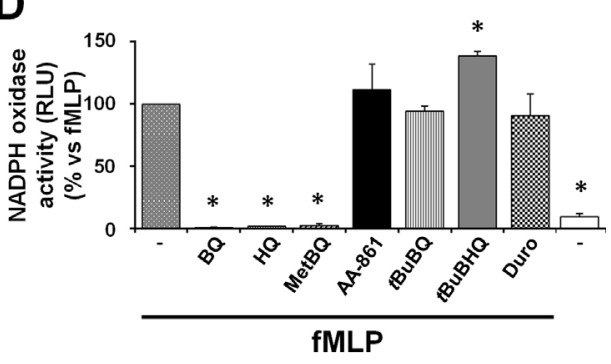

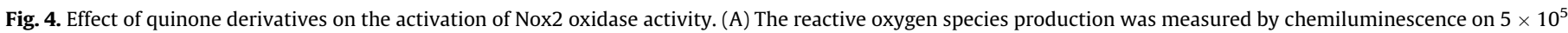

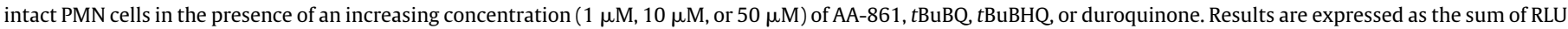

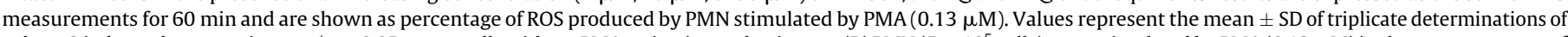

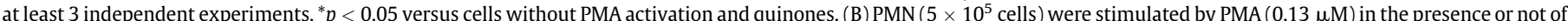

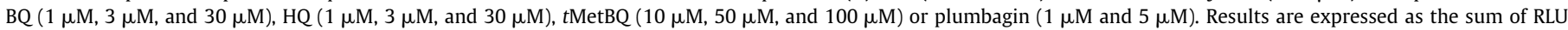

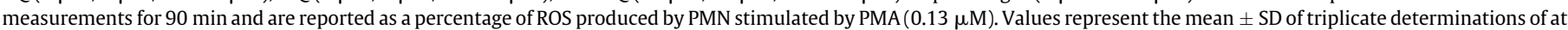

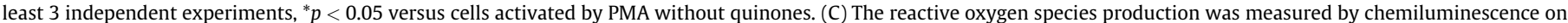

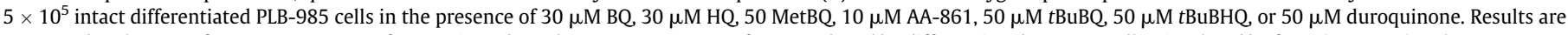

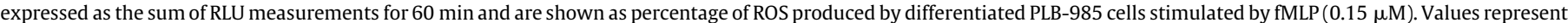

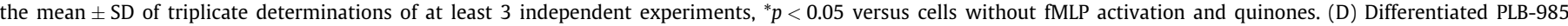

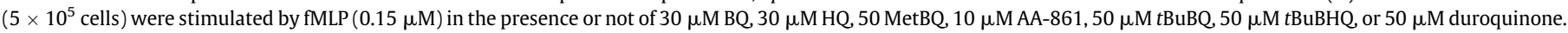

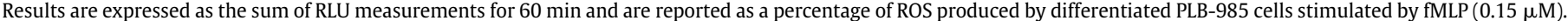
Values represent the mean \pm SD of triplicate determinations of at least 3 independent experiments, ${ }^{*} p<0.05$ versus cells activated by fMLP without quinones.

key amino acid residues of that sequence, i.e., substitutions of L203G and S209A (Fig. 5A). Our results showed that those mutations did not modify the stimulatory effect of the quinone $t$ BuBHQ on Nox4 activity which remained similar to WT Nox4 (Fig. 5B). Since our data showed that quinones did not activate Nox2 activity nor enhance its activity (Fig. 4), we therefore exchanged the sequence ${ }^{201} \mathrm{Y} . . . \mathrm{Y}^{215}$ of Nox4, which contains the putative $\mathrm{Q}$ binding of Nox4, with the homologous sequence of Nox2 ${ }^{216} \mathrm{~F} . . \mathrm{G}^{230}$. This Nox4/2 chimera protein remained still stimulated by $t$ BuBHQ (Fig. $5 \mathrm{~B}$ ). Those results suggest that this putative $\mathrm{Q}$ site domain on Nox4 is not involved in the stimulation of Nox 4 activity by quinone compounds.

\subsection{Redox regulation of Nox4 activity}

A recent study [43] showed that structural modifications of the E-loop, by deletion or exchange of cysteine, had an impact on the production rate and nature of ROS generated. The authors hypothesized that extracellular cysteines C226 and C270 might form a disulfide bridge that modulates Nox4 ROS production. Quinones compounds are highly reducing molecules capable of breaking disulfide bridges and, therefore, could modulate Nox4 activity through a redox regulation. To test this hypothesis, we measured the effect of known reducing agents on Nox4 activity and found that in tet-induced Nox4 T-REx ${ }^{\mathrm{TM}}$ cells, the addition of $80 \mu \mathrm{M}$ NADPH, NADH, or $\beta$-mercaptoethanol increased significantly the ROS production compared to non-induced and untreated Nox4 T-REx ${ }^{\mathrm{TM}}$ cells (Fig. 5C). These results suggest that reducing agents stimulate Nox 4 activity and point out a possible mechanism by which quinones might regulate Nox4 activity by reducing the E-loop disulfide bridge.

\subsection{Involvement of NQO1 on Nox4 activation by quinone}

Quinone compounds are metabolized through different pathways and one of them involves the $\mathrm{NAD}(\mathrm{P}) \mathrm{H}$ oxidoreductase 1 (NQO1). By RT-PCR and sequencing, we revealed that Nox4 T$\mathrm{REx}^{\mathrm{TM}}$ cells expressed two types of mRNA encoding for NQO1:NQ01A, the active form and NQO1C, the inactive form, which lacks 2 essential amino acid residues (Tyrosine-126 and -128) necessary for its quinone binding capacity [4]. To investigate the potential role of NQO1 in the stimulation of Nox4 activity by quinone compounds, we used dicoumarol to inhibit NQO1. Pre-incubation of the tetracycline induced Nox4 T-REx ${ }^{\mathrm{TM}}$ cells with $100 \mu \mathrm{M}$ dicoumarol inhibited Nox4 constitutive activity as well as its stimulation by $t$ BuBHQ (Fig. 6A). To further investigate the role of NQO1, we stably overexpressed NQO1A and NQO1C in Nox4HEK293 and confirmed the presence of the exogenous NQO1A and NQ01C mRNA in the corresponding transfected cells compared with the empty vector control transfected cells (Fig. 6B). Furthermore, by real time RT-PCR we showed the mRNA level of NQO1A and NQO1C increased 2 and 8 fold, respectively, compared to the control Nox4-HEK293 cells (Fig. 6B). We then investigated the consequences of these overexpressions on Nox 4 activity. Results showed that overexpression of NQO1A enhanced twice the stimulatory effect of $t \mathrm{BuBHQ}$ on Nox 4 activity compared to the control empty vector cells. This is consistent with the increase level of NQ01A mRNA observed previously (Fig. 6B). On the contrary, 
A

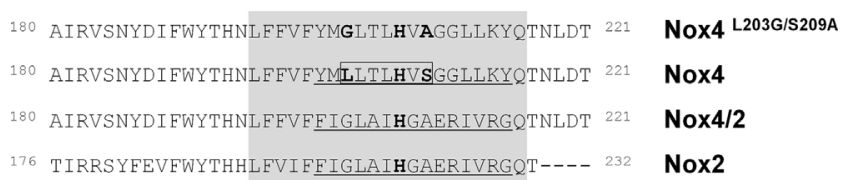

B

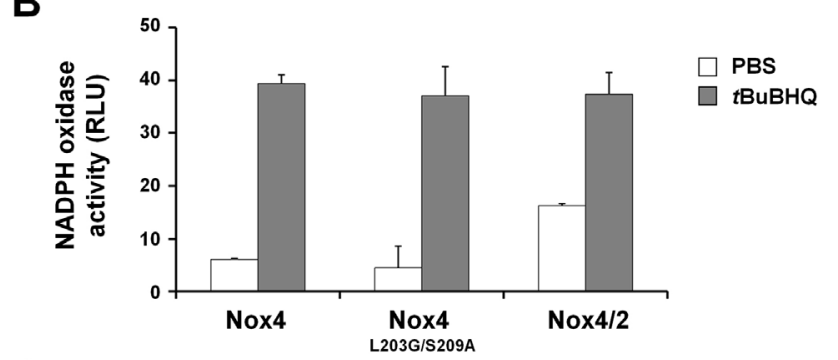

C

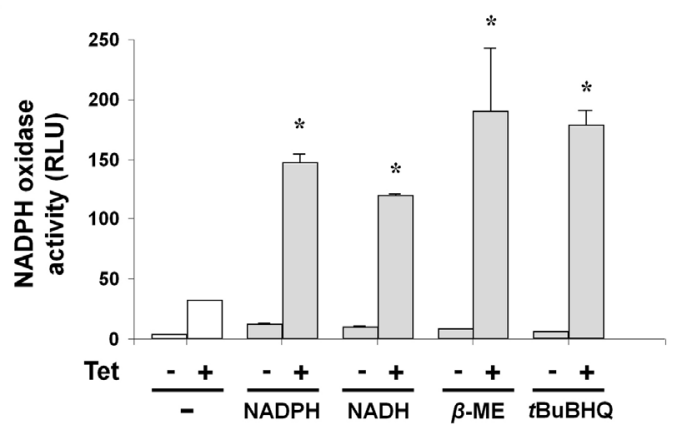

Fig. 5. Putative $Q$ site and redox regulation of Nox4 activity. (A) Schematic representation of the alignment of partial sequences of Nox4, Nox2 and Nox4 mutants (Nox4 $4^{\mathrm{L} 203 \mathrm{G} / \mathrm{S} 209 \mathrm{~A}}$ and Nox4/2). Gray box represents the predicted 5th transmembrane domain. Boxed amino acids on Nox4 sequence correspond to the putative $\mathrm{Q}$ site and bold letters are key amino acids described for the $\mathrm{Q}$ site [42]. Underlined amino acids represent amino acids that have been exchanged from Nox2 sequence to produce the chimera Nox4/2. (B) Measurement of ROS generation by chemiluminescence on $5 \times 10^{5}$ intact transfected Nox4-, Nox $4^{\text {L203G/S209A }}$ - and Nox4/2-HEK293 cells with or without $50 \mu \mathrm{M} t$ BuBHQ. (C) Measurement of ROS generation by chemiluminescence on $5 \times 10^{5}$ intact cells. ROS production by Nox 4 T-REx ${ }^{\mathrm{TM}}$ cell induced $4 \mathrm{~h}$ or not with $1 \mathrm{mg} / \mathrm{mL}$ tetracycline (tet-induced) was measured after the addition or not of NADPH, NADH, $\beta$-mercaptoethanol ( $\beta$-ME) ( $80 \mu \mathrm{M}$ of each), or $t \mathrm{BuBHQ}(50 \mu \mathrm{M})$. Results are expressed as the sum of RLU measurements for $90 \mathrm{~min}$ for each condition. Values represent the mean $\pm \mathrm{SD}$ of triplicate determinations of at least 3 independent experiments, ${ }^{*} p<0.05$ versus cells without redox compounds.

although the overexpression of $\mathrm{NQO1C}$ is higher than that of NQOA, it did not modify the stimulatory effect which is comparable to that observed with the control empty plasmid (Fig. 6C). Together, these data suggest the implication of NQO1 enzymes in quinone-stimulated Nox4 activity.

\section{Discussion}

Our study focuses on the capacity of quinone compounds to modulate the NADPH oxidase activity of Nox4. Quinones are important toxic compounds present in air pollution and abundant in all burnt organic material, including urban air particles, cigarette smoke, and diesel exhaust particles (DEP) [44]. DEP were reported to increase Nox4 ROS production after $1 \mathrm{~h}$ of incubation, suggesting the implication of Nox4 in the quinone metabolism [9]. Considering the structure/function relationship of the quinones used in this study (Table 2), we observed a dual stimulation/ inhibition effect that depends on their substitution state: Nox4 activity was stimulated by $\mathrm{AA}-861$, duroquinone, $t \mathrm{BuBQ}$ and $t \mathrm{BuBHQ}$ whereas other less substituted derivatives such as $\mathrm{BQ}, \mathrm{HQ}$

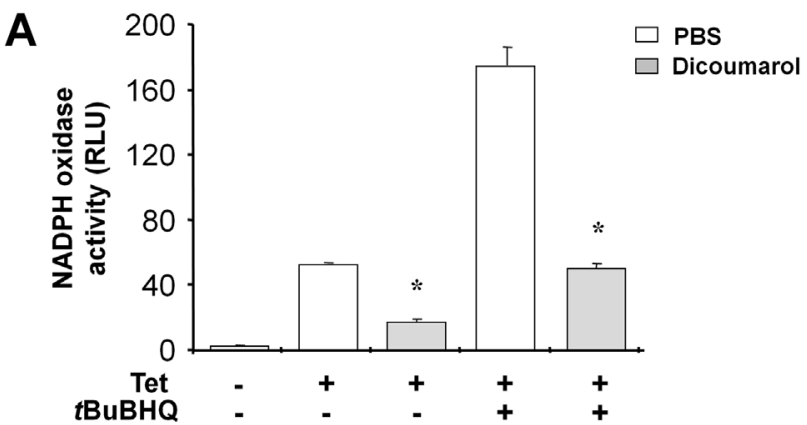

B
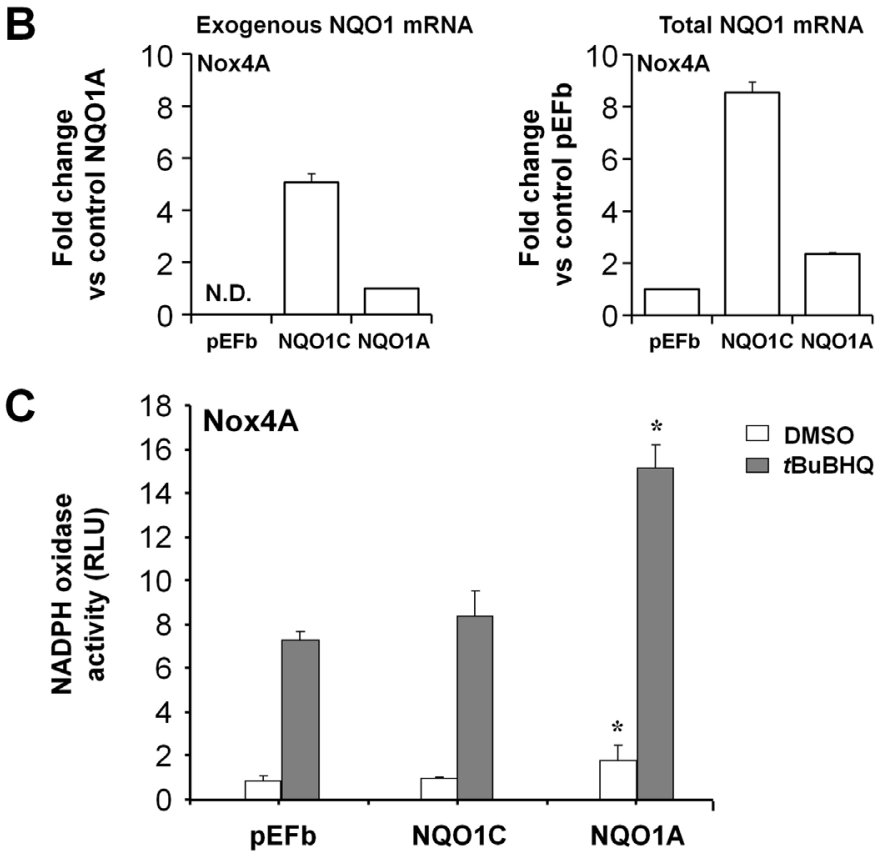

Fig. 6. Effect of NQO1 on $t$ BuBHQ activation of ROS production by Nox4. (A) Nox4 T$\mathrm{REx}^{\mathrm{TM}}$ cells were induced (or not) with $1 \mathrm{mg} / \mathrm{mL}$ tetracycline for $4 \mathrm{~h}$. Dicoumarol was added in the culture medium $2 \mathrm{~h}$ before ROS measurements. Chemiluminescence assay was done on $10^{6}$ intact cells per well, activated or not by $50 \mu \mathrm{M} t \mathrm{BuBHQ}$. Results are expressed as the sum of RLU measurements for 90 min. Values represent the mean \pm SD of triplicate determinations of at least 3 independent experiments, ${ }^{*} p<0.05$ versus cells in same condition without dicoumarol. (B) Real-time RT-PCR analysis of exogenous and total NOO1 mRNA in Nox4A-, Nox4A/NQ01C- and Nox4A/NQ01A-HEK293 cells. Left panel, real time RT-PCR showing the presence of exogenous NQ01 mRNA in Nox4A/NQO1C- and Nox4A/ NQ01A-HEK293 cells and not in Nox4A-HEK293 transfected with the control pEFb empty plasmid. N.D., not detected. Right panel, real time RT-PCR showing the increase of NQ01 mRNA level in Nox4A/NQ01C- and Nox4A/NQ01A-HEK293 cells compared to Nox4A-HEK293 transfected with the control pEFb empty plasmid. (C) Nox4A-HEK293E cells were transfected with the empty vector pEFb (Control) or containing NQO1A or NQ01B. The reactive oxygen species production was measured by chemiluminescence on $5 \times 10^{5}$ intact cells after the addition of $50 \mu \mathrm{M} t \mathrm{BuBHQ}$ or the same volume of vehicle (DMSO). Results are expressed as the sum of RLU measurements for $90 \mathrm{~min}$. Values represent the mean \pm SD of triplicate determinations of at least 3 independent experiments, ${ }^{*} p<0.005$ versus cells transfected with the control empty vector in same conditions.

$t$ MetBQ and plumbagin, developed antioxidant properties (Table 2). The specificity of AA-861, duroquinone, and $t$ BuBQ for Nox4 over Nox2, suggests either a direct effect of quinone derivatives in the molecular dynamics of electron transfer mediated by Nox4, or an indirect role on a quinone sensitive functional partner of Nox4. In this work, we suggest a new aspect of Nox4 oxidase activity regulation that takes place not only at a transcriptional level as usually described $[13,27,45]$ but also at a post-translational level as described above with quinone molecules. 
Quinones are bioreactive molecules that are sensitive to redox mechanism. Ubiquinone, for example, is a mobile electron carrier of mitochondria and a highly hydrophobic molecule that diffuses into the core of inner membrane where the electron transfer proceeds through a $\mathrm{Q}$ cycle on either side of membrane $[41,46]$. A predictable quinone binding site has been suggested [42] and we identified a similar domain in Nox4 protein sequence

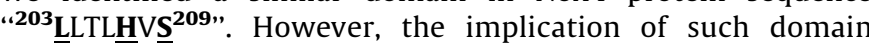
was not confirmed since the ability of quinones to stimulate Nox4 activity was not abolished when appropriate residues of this sequence were mutated (Fig. $5 \mathrm{~A}$ and $\mathrm{B}$ ).

Alternatively, Takac and his colleagues [43] have shown that disulfide bridges formed by two cysteines C226 and C270 may be involved in the maintenance of the extracellular E-loop integrity. Indeed, the disruption of the bridge by mutagenesis modified notably Nox4 ROS production [43]. Disulfide bridges with a standard redox potential $\left(E_{0}\right)$ of $-180 \mathrm{mV}$ [47] could be reduced by $\mathrm{NADPH}, \mathrm{NADH}$ and $\beta$-mercaptoethanol that possess a lower $E_{0}$ $(-324,-320$, and $-253 \mathrm{mV}$, respectively) [48]. Our results using those reducing agents indicated that Nox4 activity could be stimulated by extracellular redox modifications, possibly through the reduction of its disulfide bridge. Interestingly, duroquinone, which enhances Nox4 activity, has a low $E_{0}(-260 \mathrm{mV})$ [49] and then could theoretically reduce disulfide bridge. Conversely, compounds such as $\mathrm{BQ}, \mathrm{HQ}$ and $t$ MetBQ that do not stimulate Nox4 exhibit a higher $E_{0}, 78 \mathrm{mV}, 78 \mathrm{mV}$ and $-67 \mathrm{mV}$, respectively, compared to that of the disulfide bridge. Thus, it is possible that quinones exhibiting an $E_{0}$ lower than that of disulfide bridge are able to stimulate Nox4 activity.

$\mathrm{NAD}(\mathrm{P}) \mathrm{H}$-quinone oxidoreductase-1 (NQO1) is a broadly distributed FAD-dependent flavoprotein that catalyses the reduction of a wide variety of quinone compounds. It reduces quinones, by the transfer of 2 electrons, to the corresponding hydroquinones which are the electron donor state capable to initiate reductive reactions. We showed that NQO1 is expressed in uninduced or tetinduced Nox4 T-REx ${ }^{\mathrm{TM}}$ cells; however, the stimulation of ROS production by quinones occurs only when Nox 4 expression was induced. Moreover, the increase of Nox4 ROS production by quinones was inhibited by a well known inhibitor of NQO1, dicoumarol. Noticeably, dicoumarol also decreases Nox4 constitutive activity in quinone-untreated Tet-induced Nox4 T-REx ${ }^{\mathrm{TM}}$ cells (Fig. 6A), possibly by inhibiting the endogenous NQO1 enzymes. More specifically, only the functional NQO1 enzyme, NQO1A, enhanced the ROS production of Nox4 induced by quinone compounds (Fig. 6C). Interestingly, NQO1 has been described to partition between cytosol and plasma membrane [7] where Nox4 is also located in HEK293 cells [50]. These observations suggest a potential link between NQO1 and Nox4. Such potential link could be illustrated in pancreatic cancer. Pancreatic cancer is very aggressive and unresponsive to treatments due to a resistance of cells to apoptosis. Vaquero et al. [51] reported that ROS produced by Nox 4 are prosurvival and antiapoptotic for human pancreatic adenocarcinoma cell lines, MIA PaCa-2 and PANC-1. In the MIA PaCa-2 cell line, Lewis et al. [52] showed that inhibition of NQO1 by dicoumarol suppresses the malignant phenotype of pancreatic cancer cells and induces cell apoptosis.

Finally, our study described 4 quinones derivatives especially AA-861 and $t$ BuBHQ capable of enhancing Nox4 ROS production. We showed that NQO1 may be involved in the stimulation of Nox4 ROS production induced by quinones. We further observed that Nox 4 activity is also stimulated in the presence of reducing agents that may possibly act by reducing the disulfide bridge located in the extracellular E-loop of Nox4. All together, we hypothesize that in the presence of quinones, NQO1 may generate hydroquinone forms, providing, therefore, potential reducing agents near Nox4 protein. Depending on the quinone redox potential, Nox4 E-loop disulfide bridge could be disrupted consequently leading to the increase of its oxidase activity. However, the direct implication of the E-loop disulfide bridge needs further investigations. The proposed model could provide new insight into the understanding of molecular mechanism of the electron transfer through Nox4 and also define new therapeutic targets in diseases in which quinones and Nox4 are implicated.

\section{Acknowledgments}

This work was supported by grants from: the 'Ministère de l'Enseignement supérieur de la recherche et la technologie', Paris, France; the 'CNRS Institute'; the Association pour la Recherche contre le Cancer (ARC), Paris, France; the Région Rhône-Alpes, programme ARCUS, France/Chine 2007-2008, programme Emergence 2003-2006; the 'CGD research Trust 2006-2007', UK; the 'Groupement des Entreprises Françaises de la Lutte contre le Cancer', délégation de Grenoble; the 'UFR de Médecine, Université Joseph Fourier, Grenoble'; and the 'Direction Régionale de la Recherche Clinique, Center Hospitalier Universitaire, Grenoble'. We thank Prof. Stanke (Grenoble, France) for kindly providing the 5-lipoxygenase polyclonal antibody, Prof. P.E. Cole, Drs M.H. Huynh and M.H. Paclet for English language corrections, S. Berthier for FACS measurements, A. Dariz-Soldini for real time RT-PCR experiments and Prof. A. Maitre and Prof. R. Brandes for helpful reading and discussions.

\section{References}

[1] Bolton JL, Trush MA, Penning TM, Dryhurst G, Monks TJ. Role of quinones in toxicology. Chem Res Toxicol 2000;13:135-60.

[2] Ghio AJ, Carraway MS, Madden MC. Composition of air pollution particles and oxidative stress in cells, tissues, and living systems. J Toxicol Environ Health B Crit Rev 2012;15:1-21.

[3] Rodgman A, Smith CJ, Perfetti TA. The composition of cigarette smoke: a retrospective, with emphasis on polycyclic components. Hum Exp Toxicol 2000;19:573-95.

[4] Faig M, Bianchet MA, Talalay P, Chen S, Winski S, Ross D, et al. Structures of recombinant human and mouse $\mathrm{NAD}(\mathrm{P}) \mathrm{H}$ :quinone oxidoreductases: species comparison and structural changes with substrate binding and release. Proc Natl Acad Sci U S A 2000;97:3177-82.

[5] Kovacic P. Somanathan R. Pulmonary toxicity and environmental contamination: radicals, electron transfer, and protection by antioxidants. Rev Environ Contam Toxicol 2009;201:41-69.

[6] Auerbach A, Hernandez ML. The effect of environmental oxidative stress on airway inflammation. Curr Opin Allergy Clin Immunol 2012;12:133-9.

[7] Gray JP, Eisen T, Cline GW, Smith PJ, Heart E. Plasma membrane electron transport in pancreatic beta-cells is mediated in part by NQO1. Am J Physiol Endocrinol Metab 2011;301:E113-21.

[8] Squadrito GL, Cueto R, Dellinger B, Pryor WA. Quinoid redox cycling as a mechanism for sustained free radical generation by inhaled airborne particulate matter. Free Radic Biol Med 2001;31:1132-8.

[9] Amara N, Bachoual R, Desmard M, Golda S, Guichard C, Lanone S, et al. Diesel exhaust particles induce matrix metalloprotease-1 in human lung epithelial cells via a NADP(H) oxidase/NOX4 redox-dependent mechanism. Am J Physiol Lung Cell Mol Physiol 2007;293:L170-81.

[10] Morel F. Molecular aspects of chronic granulomatous disease. the NADPH oxidase complex. Bull Acad Natl Med 2007;191:377-90 [discussion 90-2].

[11] Lardy B, Bof M, Aubry L, Paclet MH, Morel F, Satre M, et al. NADPH oxidase homologs are required for normal cell differentiation and morphogenesis in Dictyostelium discoideum. Biochim Biophys Acta 2005;1744:199-212.

[12] Bedard K, Krause KH. The NOX family of ROS-generating NADPH oxidases: physiology and pathophysiology. Physiol Rev 2007:87:245-313.

[13] Geiszt M, Kopp JB, Varnai P, Leto TL. Identification of renox, an NAD(P)H oxidase in kidney. Proc Natl Acad Sci U S A 2000;97:8010-4.

[14] Djordjevic T, BelAiba RS, Bonello S, Pfeilschifter J, Hess J, Gorlach A. Human urotensin II is a novel activator of NADPH oxidase in human pulmonary artery smooth muscle cells. Arterioscler Thromb Vasc Biol 2005;25:519-25.

[15] Mahadev K, Motoshima H, Wu X, Ruddy JM, Arnold RS, Cheng G, et al. The $\mathrm{NAD}(\mathrm{P}) \mathrm{H}$ oxidase homolog Nox4 modulates insulin-stimulated generation of $\mathrm{H}_{2} \mathrm{O}_{2}$ and plays an integral role in insulin signal transduction. Mol Cell Biol 2004;24:1844-54

[16] Pedruzzi E, Guichard C, Ollivier V, Driss F, Fay M, Prunet $C$, et al. NAD $(P) H$ oxidase Nox-4 mediates 7-ketocholesterol-induced endoplasmic reticulum stress and apoptosis in human aortic smooth muscle cells. Mol Cell Biol 2004;24:10703-17. 
[17] Fitzgerald JP, Nayak B, Shanmugasundaram K, Friedrichs W, Sudarshan S, Eid AA, et al. Nox4 mediates renal cell carcinoma cell invasion through hypoxiainduced interleukin 6- and 8- production. PLoS ONE 2012;7:e30712.

[18] Grange L, Nguyen MV, Lardy B, Derouazi M, Campion Y, Trocme C, et al. $\mathrm{NAD}(\mathrm{P}) \mathrm{H}$ oxidase activity of Nox4 in chondrocytes is both inducible and involved in collagenase expression. Antioxid Redox Signal 2006;8:1485-96.

[19] Park HS, Chun JN, Jung HY, Choi C, Bae YS. Role of NADPH oxidase 4 in lipopolysaccharide-induced proinflammatory responses by human aortic endothelial cells. Cardiovasc Res 2006;72:447-55.

[20] Bonner MY, Arbiser JL. Targeting NADPH oxidases for the treatment of cancer and inflammation. Cell Mol Life Sci 2012;69:2435-42.

[21] Ambasta RK, Kumar P, Griendling KK, Schmidt HH, Busse R, Brandes RP. Direct interaction of the novel Nox proteins with p22phox is required for the formation of a functionally active NADPH oxidase. J Biol Chem 2004; 279:45935-41.

[22] Hilenski LL, Clempus RE, Quinn MT, Lambeth JD, Griendling KK. Distinct subcellular localizations of Nox1 and Nox4 in vascular smooth muscle cells. Arterioscler Thromb Vasc Biol 2004;24:677-83.

[23] Martyn KD, Frederick LM, von Loehneysen K, Dinauer MC, Knaus UG. Functional analysis of Nox4 reveals unique characteristics compared to other NADPH oxidases. Cell Signal 2006;18:69-82.

[24] Nguyen MV, Zhang L, Lhomme S, Mouz N, Lenormand JL, Lardy B, et al. Recombinant Nox4 cytosolic domain produced by a cell or cell-free base systems exhibits constitutive diaphorase activity. Biochem Biophys Res Commun 2012;419:453-8

[25] Nisimoto Y, Jackson HM, Ogawa H, Kawahara T, Lambeth JD. Constitutive NADPH-dependent electron transferase activity of the Nox4 dehydrogenase domain. Biochemistry 2010;49:2433-42.

[26] Ellmark SH, Dusting GJ, Fui MN, Guzzo-Pernell N, Drummond GR. The contribution of Nox4 to NADPH oxidase activity in mouse vascular smooth muscle. Cardiovasc Res 2005;65:495-504.

[27] Serrander L, Cartier L, Bedard K, Banfi B, Lardy B, Plastre O, et al. NOX4 activity is determined by mRNA levels and reveals a unique pattern of ROS generation. Biochem J 2007;406:105-14.

[28] Cucoranu I, Clempus R, Dikalova A, Phelan PJ, Ariyan S, Dikalov S, et al. NAD(P)H oxidase 4 mediates transforming growth factor-beta1-induced differentiation of cardiac fibroblasts into myofibroblasts. Circ Res 2005;97:900-7.

[29] McKallip RJ, Jia W, Schlomer J, Warren JW, Nagarkatti PS, Nagarkatti M. Cannabidiol-induced apoptosis in human leukemia cells: A novel role of cannabidiol in the regulation of p22phox and Nox4 expression. Mol Pharmacol 2006;70:897-908

[30] Moe KT, Aulia S, Jiang F, Chua YL, Koh TH, Wong MC, et al. Differential upregulation of Nox homologues of NADPH oxidase by tumor necrosis factor-alpha in human aortic smooth muscle and embryonic kidney cells. J Cell Mol Med 2006;10:231-9.

[31] Murillo MM, Carmona-Cuenca I, Del Castillo G, Ortiz C, Roncero C, Sanchez A, et al. Activation of NADPH oxidase by transforming growth factor-beta in hepatocytes mediates up-regulation of epidermal growth factor receptor ligands through a nuclear factor-kappaB-dependent mechanism. Biochem J 2007;405:251-9.

[32] Touyz RM, Chen X, Tabet F, Yao G, He G, Quinn MT, et al. Expression of a functionally active gp91phox-containing neutrophil-type $\mathrm{NAD}(\mathrm{P}) \mathrm{H}$ oxidase in smooth muscle cells from human resistance arteries: regulation by angiotensin II. Circ Res 2002;90:1205-13.

[33] Wingler K, Wunsch S, Kreutz R, Rothermund L, Paul M, Schmidt HH. Upregulation of the vascular NAD(P)H-oxidase isoforms Nox1 and Nox4 by the reninangiotensin system in vitro and in vivo. Free Radic Biol Med 2001;31:1456-64.
[34] Park HS, Jin DK, Shin SM, Jang MK, Longo N, Park JW, et al. Impaired generation of reactive oxygen species in leprechaunism through downregulation of Nox4. Diabetes 2005;54:3175-81.

[35] Campion Y, Paclet MH, Jesaitis AJ, Marques B, Grichine A, Berthier S, et al. New insights into the membrane topology of the phagocyte NADPH oxidase: characterization of an anti-gp91-phox conformational monoclonal antibody. Biochimie 2007;89:1145-58.

[36] Goyal P, Weissmann N, Rose F, Grimminger F, Schafers HJ, Seeger W, et al. Identification of novel Nox4 splice variants with impact on ROS levels in A549 cells. Biochem Biophys Res Commun 2005;329:32-9.

[37] Luo M, Lee S, Brock TG. Leukotriene synthesis by epithelial cells. Histol Histopathol 2003;18:587-95.

[38] Ding Y, Chen ZJ, Liu S, Che D, Vetter M, Chang CH. Inhibition of Nox-4 activity by plumbagin, a plant-derived bioactive naphthoquinone. J Pharm Pharmacol 2005;57:111-6.

[39] Rossary A, Arab K, Steghens JP. Polyunsaturated fatty acids modulate NOX 4 anion superoxide production in human fibroblasts. Biochem J 2007;406:7783.

[40] Tsukii K, Nakahata N, Watanabe K, Tsurufuji S, Ohizumi Y. Comparison of tBuBHQ with chemotactic peptide and phorbol ester in $\mathrm{O} 2$ - production in $\mathrm{HL}$ 60 cells. Eur J Pharmacol 1996;298:87-95.

[41] Lenaz G, Fato R, Genova ML, Bergamini C, Bianchi C, Biondi A. Mitochondrial complex I: structural and functional aspects. Biochim Biophys Acta 2006;1757:1406-20.

[42] Fisher N, Rich PR. A motif for quinone binding sites in respiratory and photosynthetic systems. J Mol Biol 2000;296:1153-62.

[43] Takac I, Schroder K, Zhang L, Lardy B, Anilkumar N, Lambeth JD, et al. The Eloop is involved in hydrogen peroxide formation by the NADPH oxidase Nox4. J Biol Chem 2011;286:13304-13.

[44] Schuetzle D, Lee FS, Prater TJ. The identification of polynuclear aromatic hydrocarbon (PAH) derivatives in mutagenic fractions of diesel particulate extracts. Int J Environ Anal Chem 1981;9:93-144.

[45] Shiose A, Kuroda J, Tsuruya K, Hirai M, Hirakata H, Naito S, et al. A novel superoxide-producing $\mathrm{NAD}(\mathrm{P}) \mathrm{H}$ oxidase in kidney. J Biol Chem 2001; 276:1417-23.

[46] Mitchell P. Protonmotive redox mechanism of the cytochrome b-c1 complex in the respiratory chain: protonmotive ubiquinone cycle. FEBS Lett 1975; 56:1-6.

[47] Siedler F, Rudolph-Bohner S, Doi M, Musiol HJ, Moroder L. Redox potentials of active-site bis(cysteinyl) fragments of thiol-protein oxidoreductases. Biochemistry 1993;32:7488-95.

[48] Crans DC, Zhang B, Gaidamauskas E, Keramidas AD, Willsky GR, Roberts CR. Is vanadate reduced by thiols under biological conditions? Changing the redox potential of $\mathrm{V}(\mathrm{V}) / \mathrm{V}(\mathrm{IV})$ by complexation in aqueous solution. Inorg Chem 2010;49:4245-56.

[49] Schultz TW. Influence of the energy relationship of organic compounds on toxicity to the cladoceran Daphnia magna and the fish Pimephales promelas. Ecotoxicol Environ Saf 1997;38:336-8.

[50] Zhang L, Nguyen MV, Lardy B, Jesaitis AJ, Grichine A, Rousset F, et al. New insight into the Nox4 subcellular localization in HEK293 cells: first monoclonal antibodies against Nox4. Biochimie 2011;93:457-68.

[51] Vaquero EC, Edderkaoui M, Pandol SJ, Gukovsky I, Gukovskaya AS. Reactive oxygen species produced by $\mathrm{NAD}(\mathrm{P}) \mathrm{H}$ oxidase inhibit apoptosis in pancreatic cancer cells. J Biol Chem 2004;279:34643-54.

[52] Lewis A, Ough M, Li L, Hinkhouse MM, Ritchie JM, Spitz DR, et al. Treatment of pancreatic cancer cells with dicumarol induces cytotoxicity and oxidative stress. Clin Cancer Res 2004;10:4550-8. 